\title{
A study on small-world characteristics of China's high-speed railway networks
}

\author{
Xin $\mathrm{YUAN}^{1 *}$, Guo LIU² and Kun Hui YE ${ }^{3}$ \\ ${ }^{1}$ Master student, Faculty of construction management and real estate, Chongqing University \\ ${ }^{2}$ PhD candidate, Faculty of construction management and real estate, Chongqing University \\ ${ }^{3}$ Professor, Faculty of construction management and real estate, Chongqing University \\ *Corresponding author's e-mail:597381055@qq.com
}

\begin{abstract}
The small-world model provides a useful perspective and method to study the topological structure and intrinsic characteristics of high-speed rail networks (HRNs). In this paper, the P-space method is used to examine global and local HRNs in China, meanwhile the adjacency matrix is developed, then the social network analysis and visualization tool UCINET is used to calculate the spatial and attribute data of HRNs at national and local levels in China. The small-world characteristics of whole HRNs are discussed, three networks which have different properties are determined, and a comparative analysis of the small-world effect is detected. Then, the relationship between the construction of high-speed rail and regional development of China is analysed. The results show that: 1) China's HRNs have small average path length $(L)$ and large clustering coefficient $(C)$, representing a typical small-world network; 2) Local HRNs have a certain correlation with economic development. The reasons for the difference of HRNs with respect to characteristics among regions are eventually discussed.
\end{abstract}

\section{KEYWORDS}

High-speed rail networks; Small world; Average path length; Clustering coefficient; China

\section{INTRODUCTION}

Network is an appropriate abstraction of things and their relationships in real world, which is compiled via nodes and edges following a certain rule. In recent years, studies of transport networks have drawn much academic enthusiasm. The investigations are concerned with airport network (Hsu and Shih 2008), urban road network (Buhl et al. 2006) and public transport network (Xu and Harriss 2008). In the public transport network, HRN which has a huge impact on urban's economy and population is a hub that connects various cities. In recent years, the rapid development of high-speed rail enables China to own a comprehensive high-speed rail system technology, the most integrated capabilities, the longest operating mileage, the highest operating speed and the largest scale under construction (Cheng 2011). Basically, small-world characteristic presents an inherent nature of network, reflects closeness of nodes in network. With this in mind, this paper is dedicated to the subject of China's HRN, exploring its topological structure and small-world characteristics at various levels. 
In 2003, China built its first high-speed rail line, opening an era of China's high-speed rail. Travelling time from one region to another has been significantly reduced. Compared with the highway, aviation and other transportation, high-speed rail has the advantages of less energy consumption, less pollution, safety, economy and little affection from climate. Because it meets the needs of people's daily transportation while reducing time cost, high-speed rail developed rapidly in recent years, and brought enormous impact on urban development, with respect to urban spatial structure (Vickerman 1995), reachability (Levinson 2012), regional tourism (Froidh 2008) and regional logistics (Lin 2015). Xiang-Mei et al. (2014) pointed out that the development of high-speed rail can facilitate population mobility, enhance regional contact degree and shorten regional economic distance. WANG Jiao'e (2014) tested that the development of high-speed rail could improve economic linkages between cities, and the impacts are various from different perspectives and regional scales.

A vast majority of existing studies have addressed more the impact of high-speed rail construction on regional development, while less on the impact of regional development on the construction of high-speed rail. Moreover, in the research area of high-speed rail, the aspects of transportation geography, economics and tourism have been attracting closer attention than the network structure. At present, many scholars have placed a couple of theoretical research and simulation on the structural complexity and space complexity of traffic network (Yu 2012), laying a useful foundation for the examination of traffic network. Complex network is the collection of a large number of real sub-systems, indicating the interaction or relationship of system elements. As a complex giant system, HRN has shown the nature of complex networks in terms of scale and characteristics. It is thus considered feasible to examine the topology and characteristics of HRN in line with the principle of complex network theory. Especially, small-world network (SWN) is employed to identity the structure and characteristics of HRNs.

Strogatz (2001) summarized the research of dynamic network, and found that network can be divided into regular network and complex network, and the latter one includes random network, SWN and self-similar network. SWN and self-similar network are between regular and random network. Watts and Strogatz (1998) proposed a network model named SWN in the study of the formation mechanism of small-world phenomena, which is deemed as regular networks, but can be recognized as random networks as well. Empirical studies show that many networks are in nature representation of SWN. Hsu and Shih (2008) conceptually applied the shortcuts of SWN to analyze alliance routes, and investigated network connectivity and efficiency of international airline alliances.

\section{Hypothesis:}

From the above discussion, public traffic network works as a SWN, there are smaller transfer times between a site and a traffic line, which reflect the connectivity and convenience of public traffic network and railway network (Yu 2012). In recent years, high-speed rail has become a new public transport in China. However, China has a vast territory, the level of economic development in different regions differ from each other. Especially, there is a great difference between eastern, central and western regions. HRN in China is subjected to various 
development statuses between regions. In considering this, hypotheseses are given below:

Hypothesis 1. China's HRNs, whether in general or local, have small-world characteristics; Hypothesis 2. Whether the small-world characteristics of HRNs in China are significant related to economic development in different regions.

\section{METHODS}

In the process of urbanization in China, the development of regional integration has gradually formed. Urban agglomeration has become a new form of spatial organization, gathering population, technology and capital. In this paper, the HRNs in Yangtze River Delta city group, Zhongyuan city agglomeration, Chengdu Chongqing city agglomeration and nationwide are adopted as research objects. Combined with regional economic development, the relationship between construction of transport infrastructure and regional development is explored. At present, there are four methods to abstract transport network: L-space, B-space, P-space and $\mathrm{C}$-space methods. In this study, P-space is adopted. Because P-space has the advantage of revealing the layout characteristics and spatial relationships of HRNs well. In P-space method, a node in a network represents a city, and edge reflects the connection between nodes, $L$ represents the number of transfers at any two sites. what's more, this article assumes that the length of the edges between any two sites are one Unit.

\section{Small-world network}

The small-world network was presented in the ground-breaking work by Watts and Strogatz (1998), in which they pointed out that real-world networks are neither completely regular networks nor completely random networks, but rather exhibit important characteristics of both. They quantified the structure properties of networks using two statistics, i.e., average path length $L$ and clushering coefficient $C$. Table 1 represents the metric name, mathematical construct and definition of $L$ and $C$.

Table 1. Network index for analysis

\begin{tabular}{lll}
\hline Metric name & Mathematical construct & \multicolumn{1}{c}{ Definition } \\
\hline $\begin{array}{l}\text { Average path } \\
\text { length }\end{array} \mathrm{L}=\frac{2}{N(N-1)} \sum_{i \gg j} d_{i j}$ & $\begin{array}{l}\text { The number of edges in the shortest path } \\
\text { between two vertices, average over all } \\
\text { pairs of vertices in the network }\end{array}$ \\
$\begin{array}{l}\text { Clushering } \\
\text { coefficient }\end{array} \quad C_{i}=\frac{2 t_{i}}{K_{i}\left(K_{i}-1\right)} \quad \mathrm{C}=\frac{1}{N} \sum_{i=1}^{N} C_{\tilde{i}}$ & $\begin{array}{l}\text { The ratio between the existing edges } \\
\text { among neighbors of a vertex and the } \\
\text { possible edges in this neighorhood }\end{array}$
\end{tabular}

Notes: $\mathbf{i}$ and $\mathbf{i}$ represents node, $\mathrm{N}$ represents the number of nodes in the network, $d_{i j}$ represents the shortest path length between $\mathrm{i}$ and $\mathbf{j} ; K_{i}$ represents the number of nearest neighbors of the node $\mathbf{i}, t_{\bar{i}}$ represents the number of edges between the neighbors of node $\mathrm{i}$.

If a network has smaller average path length and larger clustering coefficient, the network can be considered as a small-world network. Watts and Strogatz (1998) proposed the evaluation 
criteria of the small-world network, generally can be expressed as:

$$
\begin{aligned}
& \mathrm{L} \gg L_{\text {Random }} \\
& \mathrm{C} \gg C_{\text {Random }}
\end{aligned}
$$

Where, $L_{\text {Random }}$ and $C_{\text {Random }}$ represent average path length and clushering coefficient of random network, the random network has the same number of nodes and edges with the network. Because $L_{\text {Random }} \sim \ln N / \ln K$ and $C_{\text {Random }} \sim K / N$, there is the following relationship:

$$
\begin{aligned}
& L_{\text {Random }}=\ln N / \ln K \\
& C_{\text {Random }}=K / N \\
& \mathrm{~K}=2 M / N
\end{aligned}
$$

Where, $\mathrm{N}$ and $\mathrm{M}$ represent the number of nodes and edges of network, $\mathrm{K}$ represents average degree of network.

\section{Data collection}

In order to reflect the connectivity of HRNs among cities, the model of HRNs from transport level is proposed. Take the city where site is located as i, if there is a train between two cities, there is an edge named $e_{i j}$ in the network model. Figures 1, 2 respectively shown HRNs models of China, Yangtze River Delta city group, Zhongyuan city agglomeration and Chengdu Chongqing city agglomeration. Then adjacency matrix $\mathrm{A}\left(a_{i j}\right)$ is used to represent topology information contained in the model, if node $\mathrm{i}$ and node $\mathrm{i}$ are connected, $a_{i j}=1$, otherwise $a_{i j}=0$, and $\mathrm{a}_{\mathrm{ii}}=0$. For the preparation of data to make a few instructions:

(1) Take prefecture level and above cities as statistical units. Although there are small part of towns also have high-speed rail stations, but most of them lack resources to attract people, logistics and capital flows, the impacts of high-speed rail on these cities are relatively small.

(2) Data were collected from China's high-speed railway line map (March 30, 2016) and http://www.12306.cn/mormhweb/.

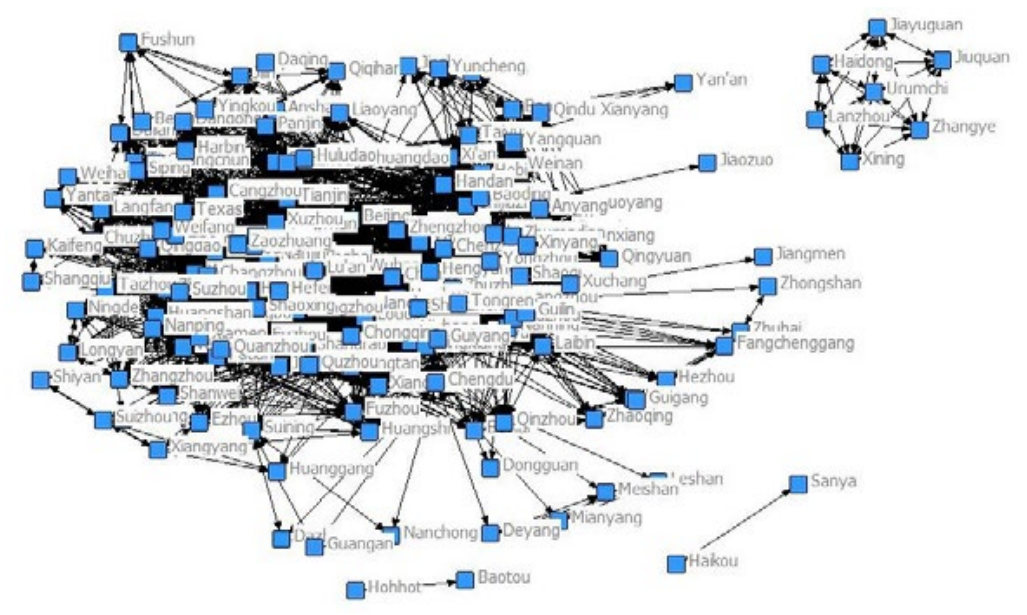

Figure 1. The model of HRNs in China 


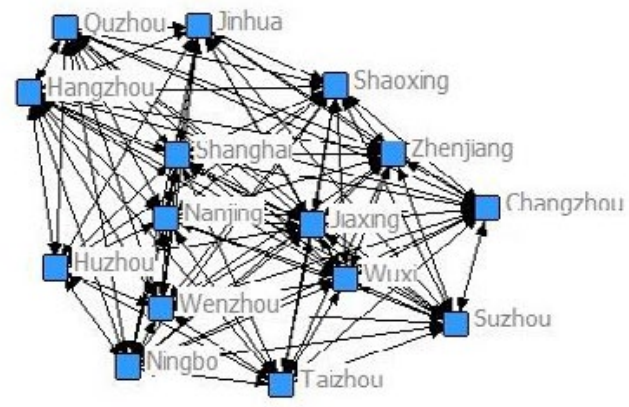

Yangtze River Delta City Group

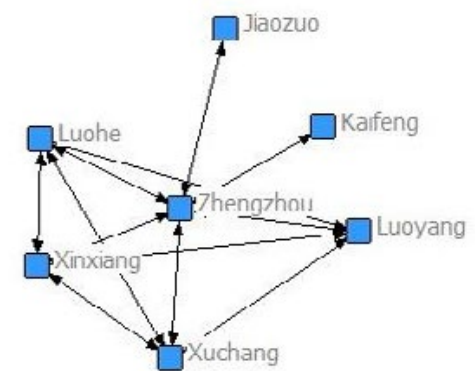

Zhongyuan city Agglomeration

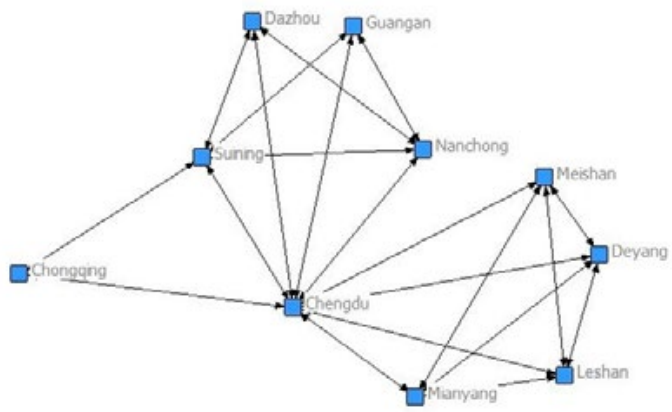

Chengdu-Chongqing Urban Agglomeration

Figure 2. The models of HRNs in three cases

\section{Data analysis}

Based on adjacency matrix, the social network analysis and visualization tool UCINET (Borgatti et al. 2002) is adopted to handle spatial data and characteristic value of networks, as shown in Tables 2 and 3.

Table 2 The characteristic value of actual network

\begin{tabular}{ccccc}
\hline $\begin{array}{l}\text { Metric } \\
\text { name }\end{array}$ & $\begin{array}{l}\text { whole } \\
\text { country }\end{array}$ & $\begin{array}{c}\text { Chengdu-Chongqing } \\
\text { Urban Agglomeration }\end{array}$ & $\begin{array}{c}\text { Zhongyuan } \\
\text { Agglomeration }\end{array}$ & $\begin{array}{c}\text { Yangtze River Delta } \\
\text { City Group }\end{array}$ \\
\hline $\mathrm{N}$ & 160 & 10 & 7 & 15 \\
$\mathrm{M}$ & 3,221 & 21 & 12 & 99 \\
$\mathrm{~L}$ & 1.864 & 1.533 & 1.429 & 1.057 \\
$\mathrm{C}$ & 0.539 & 0.733 & 0.786 & 0.971 \\
\hline
\end{tabular}

Table 3 The characteristic value of random network

\begin{tabular}{ccccc}
\hline $\begin{array}{l}\text { Metric } \\
\text { name }\end{array}$ & $\begin{array}{l}\text { whole } \\
\text { country }\end{array}$ & $\begin{array}{c}\text { Chengdu-Chongqing } \\
\text { Urban Agglomeration }\end{array}$ & $\begin{array}{c}\text { Zhongyuan } \\
\text { Agglomeration }\end{array}$ & $\begin{array}{c}\text { Yangtze River Delta } \\
\text { City Group }\end{array}$ \\
\hline $\mathrm{N}$ & 160 & 10 & 7 & 15 \\
$\mathrm{M}$ & 3,221 & 21 & 12 & 99 \\
$\mathrm{~L}$ & 1.373 & 1.605 & 1.579 & 1.050 \\
$\mathrm{C}$ & 0.252 & 0.420 & 0.490 & 0.880 \\
\hline
\end{tabular}


As shown above, HRNs in China and three urban agglomerations are relatively dense, with relatively short average path length and larger cluster coefficient, showing small-world characteristics of the network.

To compare and analyse the indexes between regions, the number of sites and train lines in Yangtze River Delta city group are far more than the other two urban agglomerations. From the point of view of average path length, the Yangtze River Delta city group has a minimum average path length, less than 2, it shows that the connectivity between cities in the Yangtze River Delta city group is very good, and average path length of other two urban agglomerations is relatively larger. The Yangtze River Delta city group has a maximum cluster coefficient, close to 1 , which shows the highest degree of concentration.

\section{RESULTS AND DISCUSSION}

Hypothesis 1. China's HRNs, whether in general or local, have small-world characteristics;

Setting: $L_{1}, L_{2}, L_{3}, L_{4}$ denote average path length of HRNs in China, Chengdu Chongqing City Agglomeration, Zhongyuan city Agglomeration and Yangtze River Delta City Group respectively. $C_{1}, C_{2}, C_{3}, C_{4}$ denote clushering coefficient of HRNs in China, Chengdu Chongqing City Agglomeration, Zhongyuan city Agglomeration and Yangtze River Delta City Group respectively.

As can be seen from the results in Table 2, $L_{1}=1.864, L_{2}=1.533, L_{3}=1.429, L_{4}=1.057$, both $\mathrm{L}_{1}$ and $\mathrm{L}_{4}$ are larger than $L_{\text {Random }}$, and are relatively small, less than 2; Although $\mathrm{L}_{2}$ and $\mathrm{L}_{3}$ are smaller than $L_{\text {Random }}$, but they are also relatively small, less than 2 . Therefore, the HRNs of China and three urban agglomerations have small average path length. $C_{1}=0.539, C_{2}=0.733, C_{3}=0.780, C_{4}=0.971, C_{1}, C_{2}, C_{3}, C_{4}$ are larger than $C_{\text {Random }}$, and are relatively large, close to 1 . Thus, the HRNs of China and three urban agglomerations might have large clushering coefficient. In summary, the hypothesis 1 is accepted.

Hypothesis 2. Whether the small-world characteristics of HRNs in China are significant related to economic development in different regions.

The three regions (Yangtze River Delta city group, Zhongyuan city agglomeration, Chengdu Chongqing urban agglomeration) can represent eastern, central and western of China. As can be seen from Table 2, although the HRNs of three urban agglomerations have shown small-world characteristics, but their significant are different. Obviously, $L_{4}\left\langle L_{3}\left\langle L_{2}, C_{4}\right\rangle C_{3}\right\rangle C_{2}$, which indicating that the small-world characteristic of HRNs in Yangtze River Delta city group is the most significant. Therefore, the hypothesis 2 is accepted.

The small-world characteristic of China's HRNs signifies that the link between cities is increasingly close, the flow of resources is smooth, which accords with China's regional integration strategy. Therefore, the construction of high-speed rail is one of ways to promote the development of regional integration. However, there are a few reasons explaining the characteristics of HRNs have distinctive difference between regions, as discussed below:

(1) Economy. In comparison with the regular railway, the construction and operation cost of 
high-speed rail is high, which needs a larger amount of capital investment. The development level of eastern China is higher than that of the central and western regions, thus the eastern region has more funds to invest in high-speed rail, which made high-speed rail in the eastern region to form a network earlier than other regions.

(2) Population. Developed area attract more people. A large number of personnel flows urge local governments to build a more convenient, faster and more affordable passenger transport facilities - high-speed rail. Therefore, HRNs of eastern regions have more nodes and edges, and its small-world characteristic is more distinctive.

(3) Geographical situation. The territory of eastern China is mainly based on the plain and hills, while the western region is dominated by the plateau, mountain and basin, which is not conducive to the development of high-speed rail. From the point of view of the technical level, although China's construction technology of high-speed rail has reached the international advanced level, but the plateau and mountainous terrain in western regions has been faced with technical problems in the construction of high-speed rail.

It can be seen from that, the differences of HRNs in characteristic between regions have a number of reasons. In a certain period of time, this difference will continue to happen. How can this difference be minimized? One of the important point is to draw on the experiences of high-speed railway construction in the eastern regions, digest and utilize these experiences, apply them to the construction of high-speed rail in the central and western regions selectively. Mainly to the following points:

(1) Striving to develop the service industry, from resource providers into service providers, attracting people, logistics and capital flows, enhanceing the needs for constructing high-speed rail.

(2) Using new technology, new material and equipment, to improve the level of high-speed rail construction, and to reduce the construction and operation cost of high-speed rail in the western regions.

(3) Implementing the strategy of introducing talents, driving economic development by science and technology progress, and promoting the coordinated development of all regions, improving the discourse power of central and western regions.

\section{CONCLUSION}

Using the empirical data, two hypotheses are demonstrated in this study. Hypothesis 1 reveals the small-world characteristics of China's HRNs from the whole and partial levels, it shows that the high-speed rail in China has become a network. Hypothesis 2, analyzing China's HRNs from the perspective of urban agglomeration, finds that the development of China's HRNs is imbalanced among urban agglomerations, and has a certain positive correlation with regional economical development. It reveals that the impact of regional development on the construction of high-speed rail goes to three aspects, namely economy, population, and geographical situation. This suggests that the planners should improve resources utilization of HRNs, balance traffic resources between urban agglomerations while in the construction of high-speed rail infrastructures. At last, some suggestions are put 
forward on how to promote the development of HRNs in the central and western regions.

This research reveals the small-world characteristics of China's HRNs. However, an in-depth analysis of the evolution of network has not been conducted. At present, research on HRNs is still relatively few, there are two aspects may become a hot spot in the future research: 1) The evolution model of HRNs and the relationship with other types of traffic network. 2) Determine the center of HRNs. Network center is a key node or edge in the network, how to determine the center of the HRNs is of great significance to the development of country and cities.

\section{REFERENCE}

Buhl, J., Gautrais, J., Reeves, N., Sole, R. V., Valverde, S., Kuntz, P., and Theraulaz, G. (2006). "Topological patterns in street networks of self-organized urban settlements." Eur Phys J B, 49(4), 513-522.

Cheng, H. Y. (2011). "Independent Innovation Creates the Miracle of High-speed Railway." Openings.

Froidh, O. (2008). "Perspectives for a future high-speed train in the Swedish domestic travel market." J Transp Geogr, 16(4), 268-277.

Hsu, C. I., and Shih, H. H. (2008). "Small-world network theory in the study of network connectivity and efficiency of complementary international airline alliances." J Air Transp Manag, 14(3), 123-129.

Levinson, D. M. (2012). "Accessibility impacts of high-speed rail." J Transp Geogr, 22, 288-291.

Lin, Y. (2015). "The influence of high-speed development to the logistics industry in our country." Journal of Jiamusi Vocational Institute.

Strogatz, S. H. (2001). "Exploring complex networks." Nature, 410(6825), 268-276.

Vickerman, R. W. (1995). "The Regional Impacts Of Trans-European Networks." Ann Regional Sci, 29(2), 237-254.

Wang Jiao'e, J. J., JIN Fengjun (2014). "Spatial effects of high-speed rails on interurban economic linkages in China." Acta Geographica Sinica, 69(12), 1833-1846.

Watts, D. J., and Strogatz, S. H. (1998). "Collective dynamics of 'small-world' networks." Nature, 393(6684), 440-442.

Xiang-Mei, L. I., Liu, Y. Z., and Cao, L. P. (2014). "Research About the Influence of Population Space of Flow Under the High-speed Railway Construction." China Population Resources \& Environment.

$\mathrm{Xu}, \mathrm{Z}$., and Harriss, R. (2008). "Exploring the structure of the U.S. intercity passenger air transportation network: a weighted complex network approach." Geojournal, 73(2), 87-102.

Yu, H. (2012). "A survey on transportation network topology and its properties." Journal of Huazhong University of Science \& Technology.

Borgatti, S. P., Everett, M. G., and Freeman, L. C. (2002). "UCINET VI for windows: Software for social network analysis." 